\author{
L. Romaka ${ }^{1}$, Yu. Stadnyk ${ }^{1}$, V.A. Romaka ${ }^{2}$, P. Klyzub ${ }^{1}$, V. Pashkevych ${ }^{2}$, \\ A. Horyn ${ }^{1}$, P. Garanyuk ${ }^{2}$
}

\title{
Synthesis and Electrical Transport Properties of $\mathrm{Er}_{1-x} \mathrm{Sc}_{x} \mathrm{NiSb}$ Semiconducting Solid Solution
}

\author{
IIvan Franko L'viv National University, L'viv, Ukraine, lyubov.romaka@gmail.com \\ ${ }^{2}$ Lviv Polytechnic National University, Lviv, Ukraine, volodymyr.romaka@ gmail.com
}

\begin{abstract}
Samples of $\mathrm{Er}_{1-x} \mathrm{Sc}_{x} \mathrm{NiSb}(x=0$ - 0.10) solid solution were synthesized by an arc-melting and the effect of doping by Sc atoms on the electrokinetic and energetic characteristics of the half-Heusler ErNiSb phase was investigated. It was established that at the studied concentrations the main carriers of electricity in the $\mathrm{Er}_{1-x} \mathrm{Sc}_{x} \mathrm{NiSb}$ semiconductor are holes. It was shown that doping of $p$-ErNiSb compound by $\mathrm{Sc}$ atoms introduced by substitution of Er atoms in $4 a$ position is accompanied by the occupation of presented vacancies in position $4 a$, which leads to the reduction and elimination of structural defects of acceptor nature and corresponding acceptor band. The concentration ratio of ionized acceptors and donors generated in $\mathrm{Er}_{1-x} \mathrm{Sc}_{x} \mathrm{NiSb}$ determines the position of the Fermi level and the mechanisms of electrical conductivity. The investigated solid solution $\mathrm{Er}_{1-x} \mathrm{Sc}_{x} \mathrm{NiSb}$ is a promising thermoelectric material.
\end{abstract}

Keywords: electrical conductivity, thermopower coefficient, Fermi level, structural defect.

Received 28 January 2021; Accepted 1 March 2021.

\section{Introduction}

One of the ways to obtain thermoelectric materials based on half-Heusler phases (structure type $\mathrm{MgAgAs}$, space group $F 4-3 m[1,2]$ ) with high efficiency of thermal energy conversion into electricity is doping of basic semiconductors, in particular, $n$-MNiSn, $n$-MCoSb and $n$-VFeSb (M = Ti, Zr, Hf), by impurity atoms, which generates structural defects of the neutral, donor and/or acceptor nature. This doping allows to change smoothly the values of the thermopower coefficient $\alpha$, the electrical conductivity $\sigma$, and the thermal conductivity $\kappa$ in a semiconductor and to obtain high values of the thermoelectric figure of merit $Z\left(Z=\alpha^{2} \cdot \sigma / \kappa\right)[2,3]$.

A new class of semiconductive thermoelectric materials of hole-type conductivity is substitutional solid solutions based on half-Heusler phases $p$-RNiSb [4], where $\mathrm{R}$ is a rare earth metal. The combination of high and positive values of the thermopower coefficient $\alpha$ with high, as for semiconductors, values of electrical conductivity $\sigma$ is the starting point to obtain thermoelectric materials with stable characteristics in a wide temperature range. Besides, positive values of thermopower coefficient $\alpha$ in $p$-RNiSb phases allow appropriate doping to obtain thermosensitive materials with positive and negative values of thermopower coefficient $\alpha$, which can also be used in thermometry to form legs of thermocouples [3, 5].

A comprehensive study of the structural, energetic, and electrokinetic characteristics of the semiconductors $p$-YNiSb, $p$-GdNiSb, $p$-ErNiSb, $p$-TmNiSb, and $p$ LuNiSb allowed to establish a model of their crystal structure, which is defective [2, 6-8]. For example, for LuNiSb compound, the most optimal is the variant of atoms distribution in the unit cell, which provides for following occupancy of the crystallographic positions: $\mathrm{Ni}(4 c)=92.65 \% \mathrm{Ni}+1.35 \% \mathrm{Lu}+6 \% \mathrm{Vac}$ $\mathrm{Lu}(4 a)=100 \% \mathrm{Lu} ; \mathrm{Sb}(4 b)=100 \% \mathrm{Sb}$. In turn, the structural defects of the LuNiSb compound in the form of vacancies in the crystallographic positions generate two energy levels (bands) of acceptor nature $\varepsilon_{\mathrm{A}}^{\mathrm{Lu}}$ and $\varepsilon_{\mathrm{A}}^{\mathrm{Ni}}$ with different depths in the semiconductor band gap. 
Calculations of the distribution of the density of states (DOS) for $p$-YNiSb and $p$-LuNiSb showed $[6,7]$ that in the optimal variant of occupancy of the crystallographic positions, the Fermi level $\varepsilon_{\mathrm{F}}$ is located near the valence band level $\varepsilon \mathrm{v}$, which correspond to the positive values of thermopower coefficient $\alpha(T, x)$ in the experiment. The calculated depth of the Fermi level $\varepsilon_{\mathrm{F}}$ relative to the valence band level in the $p$-LuNiSb is $\varepsilon_{\mathrm{F}}=$ $28.4 \mathrm{meV}$, and obtained from experimental studies $\varepsilon_{\mathrm{F}}=$ $23.9 \mathrm{meV}$. The closeness of the calculated and obtained from the experiment values of the Fermi level depth $\varepsilon_{\mathrm{F}}$ shows the correctness of the used tools for the electronic structure modeling of semiconductors [2, 6-8].

On the other hand, the presence of a significant number of structural defects in $\mathrm{RNiSb}$ compounds in several crystallographic positions at once determines the complex mechanism of entry of impurity atoms into their structure during doping. In Ref. [8] it was shown that the introduction of $\mathrm{Zr}\left(4 d^{2} 5 s^{2}\right)$ atoms into the structure of half-Heusler phase ErNiSb by substitution of $\operatorname{Er}\left(5 d^{0} 6 s^{2}\right)$ atoms in $4 a$ crystallographic position is also accompanied by the simultaneous partial occupation of the crystallographic position $4 c$ of $\mathrm{Ni}\left(3 d^{8} 4 s^{2}\right)$ atoms by impurity atoms. As a result, in the $\mathrm{Er}_{1-x} \mathrm{Zr}_{x} \mathrm{NiSb}$ semiconductor, both structural defects of donor nature at position $4 a$ ( $\mathrm{Zr}$ has a larger number of $d$-electrons than Er) and acceptor defects at position $4 c$ (Ni has more $3 d$ electrons than $\mathrm{Zr}$ ) are simultaneously generated. In this case, the energy states of impurity donor $\varepsilon_{D}^{2}$ and acceptor $\varepsilon_{\mathrm{A}}^{1}$ bands (donor-acceptor pairs) appear in the band gap of the semiconductor $\mathrm{Er}_{1-x} \mathrm{Zr}_{x} \mathrm{NiSb}$, which determine its conduction mechanisms. The study of $\mathrm{Tm}_{1-x} \mathrm{Sc}_{x} \mathrm{NiSb}$ solid solution showed that the substitution of rare earth $\mathrm{Tm}$ atoms by $\mathrm{Sc}$ atoms does not change the type of majority current carriers and the holes remain the main carriers of electricity [9].

In the present paper, the first results of experimental studies of new thermoelectric material based on an $\mathrm{Er}_{1-x} \mathrm{Sc}_{x} \mathrm{NiSb}$ semiconductor solid solution obtained by doping of ErNiSb half-Heusler phase by Sc atoms in the way of $\mathrm{Er}$ atoms substitution in $4 a$ position were reported. The $\mathrm{ScNiSb}$ compound, which is the opposite to ErNiSb end member of solid solution $\mathrm{Er}_{1-x} \mathrm{Sc}_{x} \mathrm{NiSb}$ at $x=1$, is also a semiconductor with hole-type of conduction, and its thermopower coefficient reaches maximum values $\alpha=240 \mu \mathrm{V} / \mathrm{K}$ at $450 \mathrm{~K}$ [10]. It was stated by authors of Ref. [10] that the vacancies, which generate structural defects of acceptor nature in $4 c$ position and form the corresponding acceptor band, are responsible for the hole type of conduction of $p$-ScNiSb. Therefore, the substitution of rare earth metal Er atoms by Sc atoms, which are in the same group of the Periodic table of elements, should allow obtaining a continuous semiconductor solid solution $\mathrm{Er}_{1-x} \mathrm{Sc}_{x} \mathrm{NiSb}$ of hole-type of conduction with a smooth change of its parameters. The results of the study of the electrokinetic and energetic characteristics of $\mathrm{Er}_{1-x} \mathrm{Sc}_{x} \mathrm{NiSb}$ solid solution, $x=0-0.10$, will provide identification of the mechanisms of electrical conduction to define the conditions for the synthesis of thermoelectric materials with maximum efficiency of conversion of thermal energy into electricity.

\section{Experimental details}

Synthesis of the samples of $\mathrm{Er}_{1-x} \mathrm{Sc}_{x} \mathrm{NiSb}$ solid solution $(x=0-0.1)$ was performed by arc melting of the constituent elements (the content of the main component is not less than $99.9 \mathrm{wt}$ \%) in an electric arc furnace under an inert argon atmosphere (spongy titanium used as a getter). For better homogenization, the alloys were re-melted twice. Compensation for loss of antimony during the melting process was provided by an excess of 2 wt. \% Sb. Heat treatment of samples consisted of homogenizing annealing at $1070 \mathrm{~K}$ in vacuum quartz ampoules for a month. After annealing, the alloys were quenched in cold water without breaking the ampoule. For X-ray phase analysis of the synthesized alloys and calculation of structural parameters, the diffraction data obtained on a DRON-4.0 diffractometer ( $\mathrm{Fe} K \alpha$ radiation) were used. Crystallographic parameters of $\mathrm{Er}_{1-x} \mathrm{Sc}_{x} \mathrm{NiSb}$ samples were calculated with the Fullprof Suite program package [11]. The distribution of the elements, chemical and phase compositions of the samples were examined by energy dispersive X-ray spectral analysis (EDRS, Tescan Vega 3 LMU scanning electron microscope). Temperature and concentration dependencies of electrical resistivity $(\rho)$ (two-probe method) and thermopower coefficient $(\alpha)$ (in relation to the pure copper) for $\mathrm{Er}_{1-x} \mathrm{Sc}_{x} \mathrm{NiSb}$ solid solution samples were measured in the ranges $T=80-400 \mathrm{~K}, x=0-0.10$. The algorithm presented in Ref. [12] was used for modeling the electronic structure.

\section{Crystalline and electronic structures modeling of $\mathrm{Er}_{1-x} \mathrm{Sc}_{x} \mathrm{NiSb}$}

Microprobe analysis of the atom concentration on the surface of $\mathrm{Er}_{1-x} \mathrm{Sc}_{x} \mathrm{NiSb}$ samples established their correspondence to the initial compositions of the charge, and, as an example, a map of the elemental distribution of components according to X-ray spectral analysis (EDRS) for $\mathrm{Er}_{0.97} \mathrm{Sc}_{0.03} \mathrm{NiSb}$ sample is shown in Fig. 1,a. According to the results of X-ray analysis, the powder patterns of $\mathrm{Er}_{1-x} \mathrm{Sc}_{x} \mathrm{NiSb}$ samples up to Sc content $x=0$ 0.10 , are indexed in the $\mathrm{MgAgAs}$ structure type [1] and do not contain traces of impurity phases (Fig. 1,b). The obtained results indicate the homogeneity of $\mathrm{Er}_{1-x} \mathrm{Sc}_{x} \mathrm{NiSb}$ samples.

Since the atomic radius $\mathrm{Sc}\left(r_{\mathrm{Sc}}=0.164 \mathrm{~nm}\right)$ is smaller than $\operatorname{Er}\left(r_{\mathrm{Er}}=0.176 \mathrm{~nm}\right)$, the decrease in the values of the lattice parameter $a(x)$ of the $\mathrm{Er}_{1-x} \mathrm{Sc}_{x} \mathrm{NiSb}$ samples is clear (Fig. 1,b). At concentrations $x>0.03$, the angle of inclination of the dependence $a(x)$ changes only slightly. This behavior of $a(x)$ for $\mathrm{Er}_{1-x} \mathrm{Sc}_{x} \mathrm{NiSb}$ confirmed the formation of a substitutional solid solution, where $\mathrm{Sc}$ atoms can occupy vacancies in position $4 a$ and replace Er atoms in the same position.

The refinement of the crystal structure of $\mathrm{Er}_{1-x} \mathrm{Sc}_{x} \mathrm{NiSb}$ by the powder method with the simultaneous refinement of the isotropic parameters of atomic displacement and the occupancy of the $4 a$ crystallographic position due to the low concentration of Sc impurity atoms did not reveal a structural disordering, 

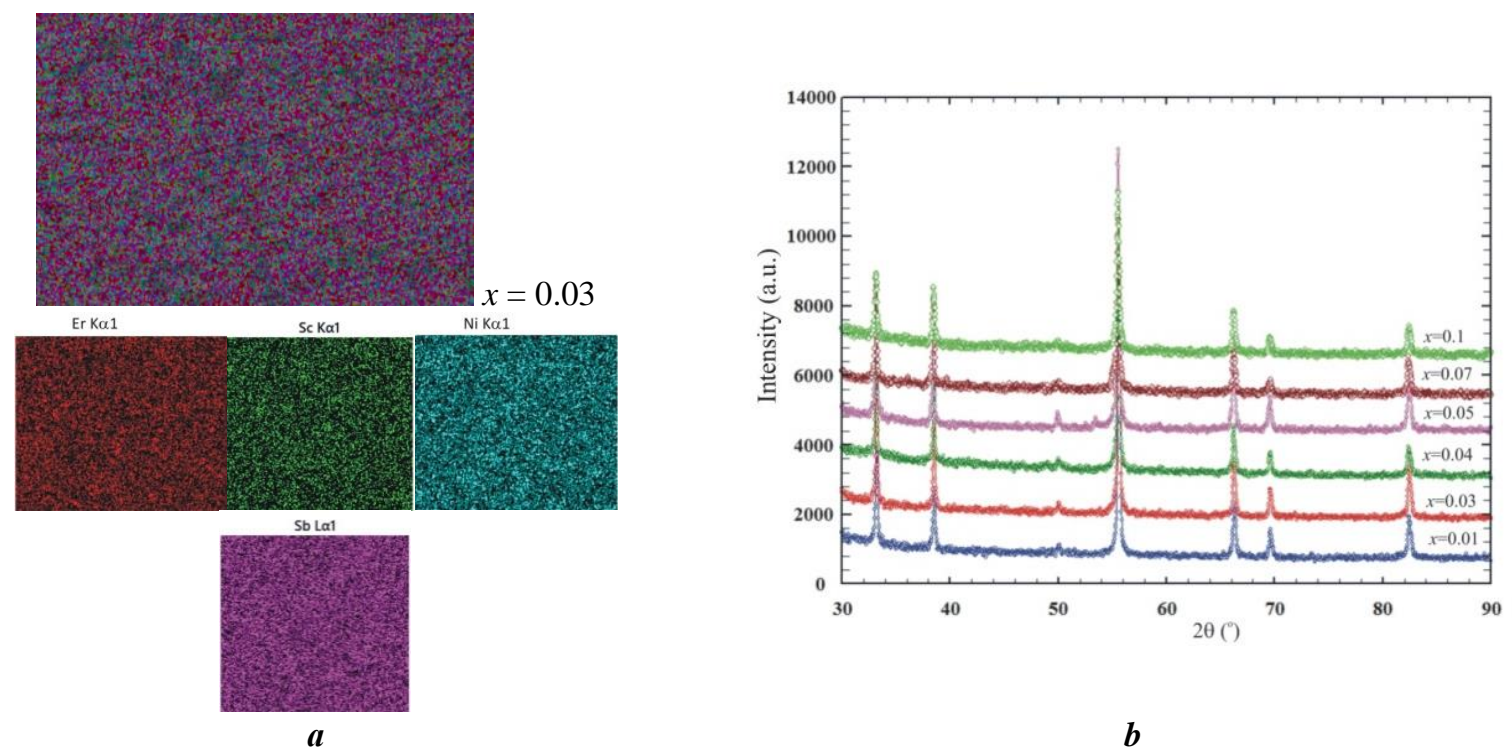

Fig. 1. Distribution of the components for the $\mathrm{Er}_{0.97} \mathrm{Sc}_{0.03} \mathrm{NiSb}$ sample (EDRS data) (a); powder patterns of the $\mathrm{Er}_{1-\mathrm{x}} \mathrm{Sc}_{\mathrm{x}} \mathrm{NiSb}$ samples $(\boldsymbol{b})$.

where Sc atoms would occupy other positions or tetrahedral voids, which constitute $\sim 24 \%$ of the unit cell volume [1, 2].

The electronic structure of the $p$-ErNiSb semiconductor is similar to $p$-LuNiSb $[2,6]$, in which the Fermi level $\varepsilon_{F}$ is located in the band gap $\varepsilon_{g}$ near the percolation level of the valence band $\varepsilon_{V}$, and the holes are the main carriers of electricity. In the experiment, the positive values of the thermopower coefficient $\alpha(T, x)$ have to be obtained.

At low concentrations of Sc impurity atoms $(x=$ $0.01)$, their occupation of the vacancies in the ErNiSb compound in position $4 a$ of Er atoms "heals" structural defects of acceptor nature and will lead to a decrease of their concentration. As a result, in the band gap $\varepsilon_{g}$ of $\mathrm{Er}_{1-x} \mathrm{Sc}_{x} \mathrm{NiSb}$, the concentration of acceptors of the corresponding acceptor level (band) $\varepsilon_{A}^{E r}$ will decrease, and the contribution of free holes in the conductivity of the semiconductor will also decrease. In this case, the semiconductor $\mathrm{Er}_{1-x} \mathrm{Sc}_{x} \mathrm{NiSb}$ becomes compensated and the Fermi level $\varepsilon_{\mathrm{F}}$ will move towards the middle of the band gap $\varepsilon_{\mathrm{g}}$ but will remain closer to the percolation level of the valence band $\varepsilon \mathrm{v}$. Taking into account that in the $p$ ErNiSb and $p$ - $\mathrm{Er}_{0.99} \mathrm{Sc}_{0.01} \mathrm{NiSb}$ semiconductors the Fermi level $\varepsilon_{\mathrm{F}}$ is located in the band gap $\varepsilon_{\mathrm{g}}$, then the hightemperature activation parts would be presented on the temperature dependences of the resistivity $\ln (\rho(1 / T))$, which is a manifestation of thermal activation of the holes from the impurity acceptor band $\varepsilon_{\mathrm{A}}^{E r}$ to the percolation level of the valence band $\varepsilon_{V}$ with the activation energy of the band $\varepsilon_{1}^{\rho}$.

At higher concentrations of Sc atoms, when all vacancies in position $4 a$ are filled and structural defects of acceptor nature are eliminated, the acceptor level $\varepsilon_{\mathrm{A}}^{E r}$ disappears in the band gap of the $\mathrm{Er}_{1-x} \mathrm{Sc}_{x} \mathrm{NiSb}$ semiconductor. Thus, the substitution of $\operatorname{Er}\left(5 d^{0} 6 s^{2}\right)$ atoms by $\mathrm{Sc}\left(3 d^{1} 4 s^{2}\right)$ ones in position $4 a$ will lead to the generation of structural defects of donor nature and the appearance of the impurity donor level (band) $\varepsilon_{D}^{S c}$ in the

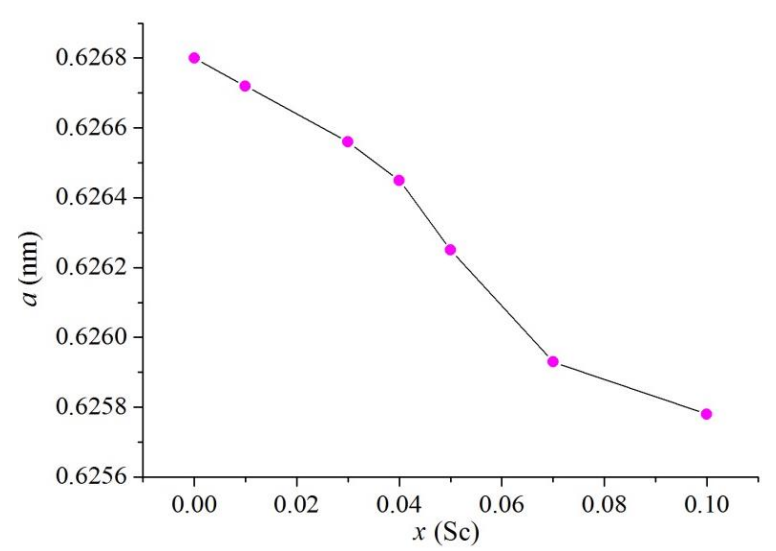

Fig. 2. Variation of the unit cell parameter $a(x)$ for $\mathrm{Er}_{1-\mathrm{x}} \mathrm{Sc}_{\mathrm{x}} \mathrm{NiSb}$.

band gap $\varepsilon_{g}$, because the Sc atom has more electrons on the outer electron shells than the Er atom. The ratio of the present in $\mathrm{Er}_{1-x} \mathrm{Sc}_{x} \mathrm{NiSb}$ ionized states of the acceptor band $\varepsilon_{\mathrm{A}}^{N i}$, generated by vacancies in the crystallographic position $4 c$ of $\mathrm{Ni}$ atoms, and the states of the impurity donor band $\varepsilon_{D}^{S c}$ will determine the position of the Fermi level $\varepsilon_{F}$ in the band gap $\varepsilon_{g}$ of the semiconductor. The $\mathrm{Er}_{1-x} \mathrm{Sc}_{x} \mathrm{NiSb}$ semiconductor will be heavily doped and highly compensated [13]. The presented below results of experimental measurements of the electron transport properties of the $\mathrm{Er}_{1-x} \mathrm{Sc}_{x} \mathrm{NiSb}$ solid solution will show the correspondence of modeling results to real processes in the semiconductor.

\section{Study of electrokinetic and energetic characteristics of $\mathrm{Er}_{1-x} \mathrm{Sc}_{x} \mathrm{NiSb}$}

To measure the electrical transport characteristics 
samples with Sc content $x=0,0.01,0.03,0.05,0.1$, were selected and prepared in the form of parallelepipeds by electrospark cutting. The temperature and concentration dependencies of the electrical resistivity $\rho$ and thermopower coefficient $\alpha$ for $\quad \mathrm{Er}_{1-x} \mathrm{Sc}_{x} \mathrm{NiSb}$ semiconductor are shown in Figs. 3, 4. As we can see from Fig. 3, $\ln (\rho(1 / T))$ dependencies of the $\mathrm{Er}_{1-x} \mathrm{Sc}_{x} \mathrm{NiSb}$ samples are typical for semiconductors [13] and can be approximated by known relation (1):

$\rho^{-1}(T)=\rho_{1}^{-1} \exp \left(-\frac{\varepsilon_{1}^{\rho}}{k_{B} T}\right)+\rho_{3}^{-1} \exp \left(-\frac{\varepsilon_{3}{ }^{\rho}}{k_{B} T}\right)$,

where the first high-temperature term describes the activation of current carriers $\varepsilon_{1}^{\rho}$ from the Fermi level $\varepsilon_{F}$ to the percolation level of the continuous energy bands,

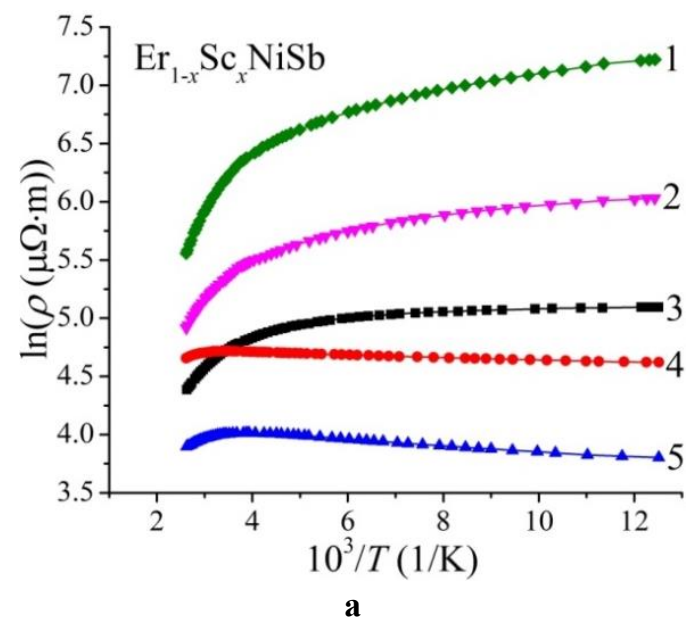

the second low-temperature term - hopping conductivity on impurity donor states $\varepsilon_{3}^{\rho}$ with energy values close to the Fermi level $\varepsilon_{F}$.

In turn, the temperature dependences of the thermopower coefficient $\alpha(1 / T)$ of $\mathrm{Er}_{1-x} \mathrm{Sc}_{x} \mathrm{NiSb}$ (Fig. 3) are described by the known relation (2) [14]:

$$
\alpha=\frac{k_{B}}{e}\left(\frac{\varepsilon_{i}^{\alpha}}{k_{B} T}-\gamma+1\right),
$$

where $\gamma$ is a parameter which depends on the nature of the scattering mechanism. From the high-temperature part of the $\alpha(1 / T)$ dependence the values of the activation energy $\varepsilon_{1}^{\alpha}$ are calculated, which, as shown in [2], are proportional to the amplitude of large-scale fluctuations of the continuous energy bands of heavily doped and

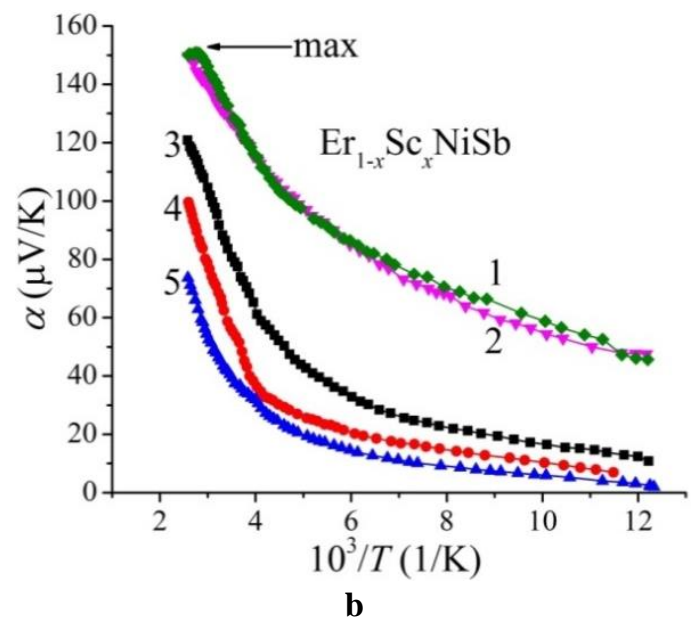

Fig 3. Temperature dependencies of the electrical resistivity $\ln (\rho(1 / T))(\mathbf{a})$ and thermopower coefficient $\alpha(1 / T)(\mathbf{b})$ for $\mathrm{Er}_{1-\mathrm{x}} \mathrm{Sc}_{\mathrm{x}} \mathrm{NiSb}: 1-x=0.10,2-x=0.05,3-x=0.03,4-x=0.01,5-x=0$.
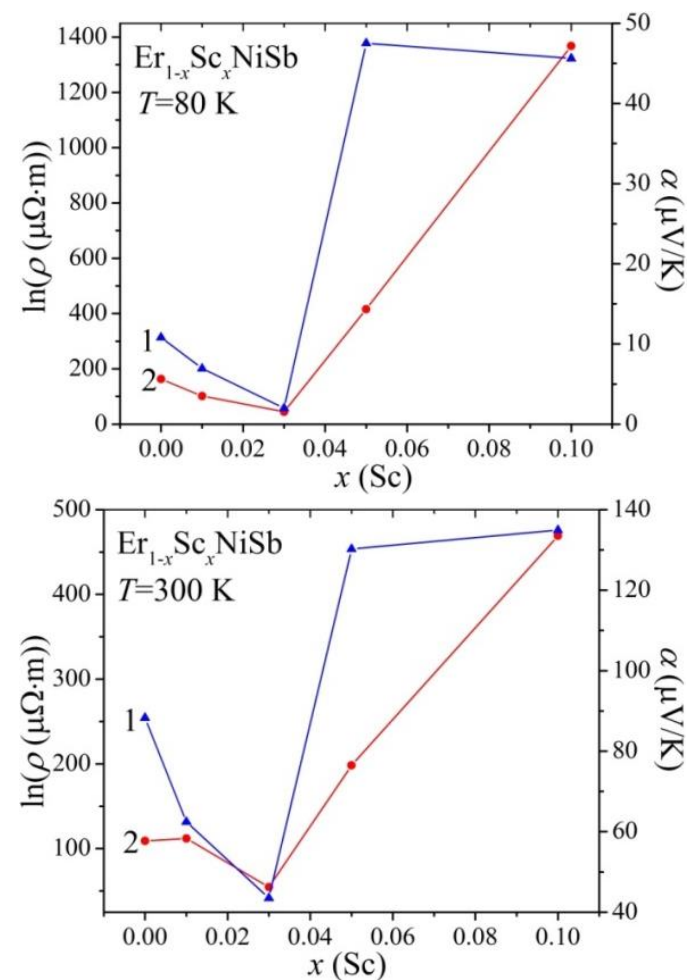
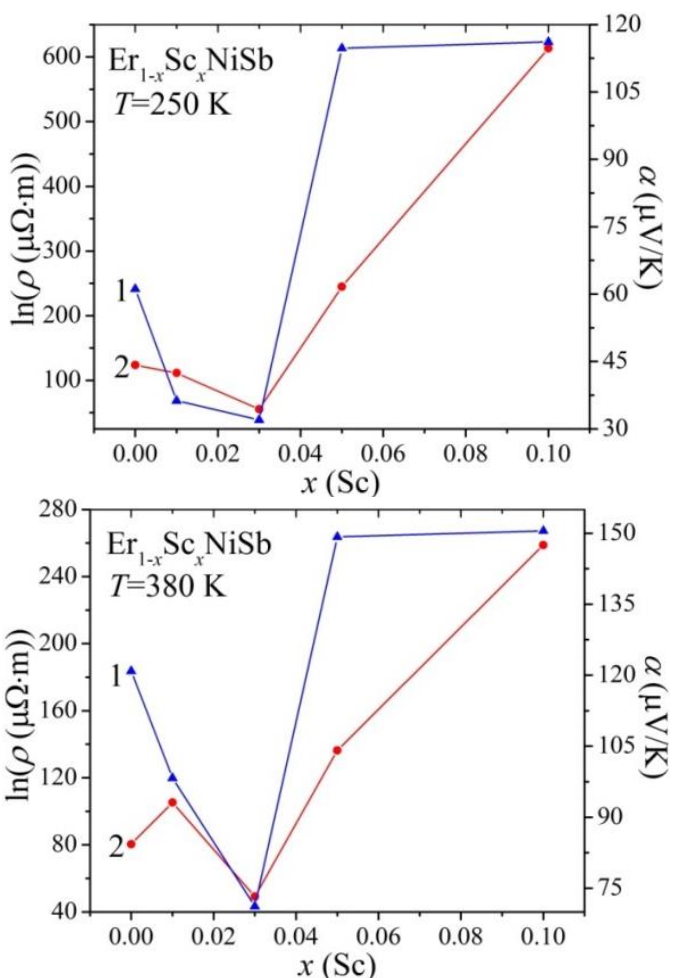

Fig. 4. Variation of thermopower coefficient $\alpha(x, T)(\mathbf{1})$ and the electrical resistivity values $\rho(x, T)(\mathbf{2})$ for $\mathrm{Er}_{1-\mathrm{x}} \mathrm{Sc}_{\mathrm{x}} \mathrm{NiSb}$ at different temperatures. 
compensated semiconductor [13].

The character of the variation of the resistivity values $\ln (\rho 1 / T))$ at high temperatures for all studied $\mathrm{Er}_{1-x} \mathrm{Sc}_{x} \mathrm{NiSb}$ samples (presence of high-temperature activation parts) (Fig. 3) indicates the location of the Fermi level $\varepsilon_{F}$ in the band gap of the semiconductor, and positive values of the thermopower coefficient $\alpha(x, T)$ (Figs. 3, 4) clarify its position near percolation level of the valence band $\varepsilon_{V}$. The positive values of the thermopower coefficient $\alpha(x, T)$ for all concentrations of Sc atoms are consistent with the electronic structure modeling of $\mathrm{Er}_{1-x} \mathrm{Sc}_{x} \mathrm{NiSb}$.

In turn, for $p$-ErNiSb, the presence of a lowtemperature activation part with activation energy $\varepsilon_{3}^{\rho}=$ $0.4 \mathrm{meV}$ on the $\ln (\rho(1 / T))$ dependence indicates the compensation of the sample, which will be provided by defects of acceptor and donor nature of unknown origin. However, in the $\mathrm{Er}_{1-x} \mathrm{Sc}_{x} \mathrm{NiSb}$ samples, $x=0.01$ and $x=$ 0.03 , activation parts are absent due to the increase of acceptors concentration when the radii of localization of the holes intersect.

A decrease of the electric resistivity $\rho(x, T)$ and thermopower coefficient $\alpha(x, T)$ values (Fig. 4) in the concentration range $x=0-0.03$ indicates an increase of the holes concentration for $p-\mathrm{Er}_{1-x} \mathrm{Sc}_{x} \mathrm{NiSb}$. Doping of ErNiSb by the lowest in the experiment Sc impurity content, as for example at $T=80 \mathrm{~K}$, leads to a decrease of $\sim 4$ times $\rho(x, T)$ values: from $\rho_{x=0}=163.3 \mu \Omega \cdot \mathrm{m}$ to $\rho_{x=0.01}=101.7 \mu \Omega \cdot \mathrm{m}$ and $\rho_{x=0.03}=44.8 \mu \Omega \cdot \mathrm{m}$. The values of the thermopower coefficient $\alpha(x, T)$ decrease also at all the temperatures, as for example, at $T=380 \mathrm{~K}$, from $\alpha_{x=0}=120.9 \mu \mathrm{V} / \mathrm{K}$ to $\alpha_{x=0.01}=98.3 \mu \mathrm{V} / \mathrm{K}$ and $\alpha_{x=0.03}=$ $71.2 \mu \mathrm{V} / \mathrm{K}$. For $p$-type semiconductor, it is possible only if the concentration of the main current carriers, which are holes, increases.

However, the reason for such an increase of the hole concentration in $\mathrm{Er}_{1-x} \mathrm{Sc}_{x} \mathrm{NiSb}$ at Sc concentration $x=0$ 0.03 is not completely clear. The assumption, by analogy with $\mathrm{Er}_{1-x} \mathrm{Zr}_{x} \mathrm{NiSb}$ [8], about the possible occupation of $4 c$ crystallographic position of $\mathrm{Ni}\left(3 d^{8} 4 s^{2}\right)$ atoms by $\mathrm{Sc}$ atoms and the generation of structural defects of acceptor nature ( $\mathrm{Sc}$ has fewer $3 d$-electrons than $\mathrm{Ni}$ ) is not confirmed by the behavior of the lattice parameter $a(x)$ of $\mathrm{Er}_{1-x} \mathrm{Sc}_{x} \mathrm{NiSb}$ (Fig. 2). If the $4 c$ position of $\mathrm{Ni}$ atoms $\left(r_{\mathrm{Ni}}=\right.$ $0.124 \mathrm{~nm}$ ) was at least partially occupied by Sc atoms $\left(r_{\mathrm{Sc}}=0.164 \mathrm{~nm}\right)$, this would lead to a rapid increase in the values of lattice parameter $a(x)$ of $\mathrm{Er}_{1-x} \mathrm{Sc}_{x} \mathrm{NiSb}$, but this is not observed. This question requires additional studies of the $\operatorname{Er}_{1-x} \mathrm{Sc}_{x} \mathrm{NiSb}$ solid solution at higher concentrations of Sc impurity atoms.

The rapid increase of the acceptors concentration in $\mathrm{Er}_{1-x} \mathrm{Sc}_{x} \mathrm{NiSb}$ at low concentrations of impurity atoms was also indicated by the character of the change in the activation values of holes $\varepsilon_{1}^{\rho}$ from the Fermi level $\varepsilon_{F}$ to the percolation level of the valence band $\varepsilon_{V}$ (Fig. 5).

In $p$-ErNiSb the Fermi level $\varepsilon_{F}$ was located at a distance of $45.4 \mathrm{meV}$ from the percolation level of the valence band $\varepsilon_{V}$, while in $\mathrm{Er}_{1-x} \mathrm{Sc}_{x} \mathrm{NiSb}$ at the concentration $x=0.01$, the Fermi level $\varepsilon_{F}$ shifted towards the valence band $\varepsilon_{V}$ and was located at a distance of $13.6 \mathrm{meV}$ from its percolation level. Since the Fermi level $\varepsilon_{F}$ represents the ratio of ionized acceptors and donors in the semiconductor, its movement at $x=0.01$ to the percolation level of the valence band $\varepsilon_{V}$ is possible

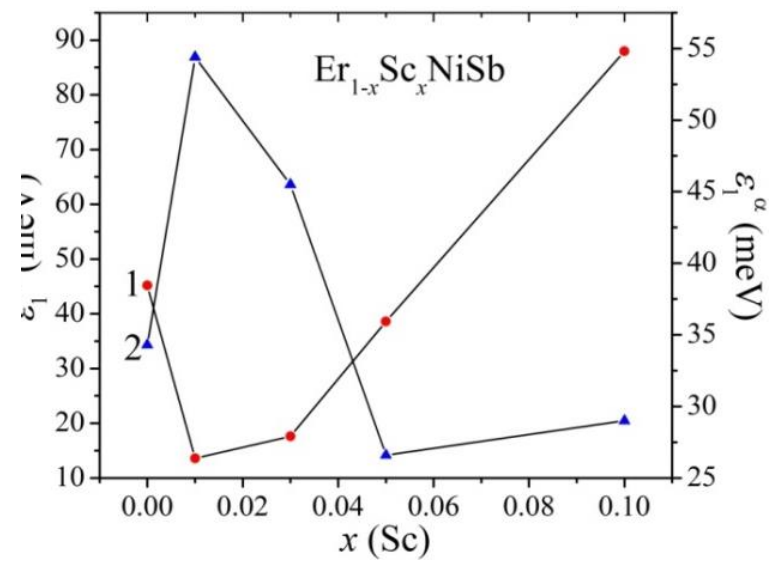

Fig. 5. Variation of the energy activation values $\varepsilon_{1}{ }^{\rho}$ (1) and $\varepsilon_{1}^{\alpha}(2)$ for $\mathrm{Er}_{1-\mathrm{x}} \mathrm{Sc}_{\mathrm{x}} \mathrm{NiSb}$.

either if the acceptor number increases or the concentration of ionized donors decreases rapidly (which is unlikely). At a higher concentration of acceptor impurity, $x=0.03$, the Fermi level $\varepsilon_{F}$ only slightly, within the experimental error, deviated from the percolation level of the valence band $\varepsilon_{V}$ at a distance of $17.1 \mathrm{meV}$. This is possible only if a compensatory impurity appears in the semiconductor, namely donors as a result of the substitution of Er atoms by Sc. Herewith the concentration of donors is still insignificant because at low temperatures there is no hopping mechanism of electrical conductivity $\varepsilon_{3}^{\rho}$ in the $\operatorname{Er}_{0.97} \mathrm{Sc}_{0.03} \mathrm{NiSb}$ semiconductor. It can be stated that in the $\mathrm{Er}_{1-x} \mathrm{Sc}_{x} \mathrm{NiSb}$ semiconductor in the concentration range $x=0-0.03$ the number of generated acceptors far exceeds the donor concentration.

At even higher concentrations of Sc impurity in $p$-Er ${ }_{1-x} \mathrm{Sc}_{x} \mathrm{NiSb}, x \geq 0.03$, the characteristics of the semiconductor change considerably. Low-temperature activation regions appear on the $\ln (\rho(1 / T))$ dependences, which is a feature of compensation and evidence of the simultaneous generation of structural defects of acceptor and donor nature in the crystal: the semiconductor becomes heavily doped and compensated. This is also indicated by the behavior of the position of the Fermi level in the band gap of the $\operatorname{Er}_{1-x} \mathrm{Sc}_{x} \mathrm{NiSb}$ semiconductor, which according to the linear law (Fig. 5) moves away from the percolation level of the valence band $\varepsilon_{V}: \varepsilon_{1}^{\rho}(x=$ $0.05)=38.6 \mathrm{meV}$ and $\varepsilon_{1}^{\rho}(x=0.10)=88.1 \mathrm{meV}$. Such motion of the Fermi level $\varepsilon_{F}$ upon doping of a semiconductor of the hole-type conductivity is possible only under the condition of donor generation. This behavior of the Fermi level $\varepsilon_{F}$ was predicted because with increasing concentration of Sc atoms the acceptor band $\varepsilon_{A}^{E r}$ is depleted due to occupation of available vacancies by $\mathrm{Sc}$ atoms which simultaneously generates structural defects of donor nature and forms an impurity donor band $\varepsilon_{D}^{S c}$.

The appearance of donors in the $p$ - $\mathrm{Er}_{0.90} \mathrm{Sc}_{0.10} \mathrm{NiSb}$ semiconductor is indicated by the character of variation of the thermopower coefficient values $\alpha(1 / T)$ (Fig. 3), in 
particular, the change in the slope of the dependence (extremum) at high temperatures. We can predict that at higher temperatures the thermopower coefficient will change its sign.

The behaviour of the electrical resistivity $\rho(x, T)$ and thermopower coefficient $\alpha(x, T)$ dependencies for $p$ - $\mathrm{Er}_{1-x} \mathrm{Sc}_{x} \mathrm{NiSb}, x \geq 0.03$, (Fig. 4) also indicated the appearance of donors in the semiconductor. Thus, in the concentration range, $x=0.03-0.10$, for $\mathrm{Er}_{1-x} \mathrm{Sc}_{x} \mathrm{NiSb}$ electrical resistivity values $\rho(x, T)$ increase rapidly, for example, at $T=80 \mathrm{~K}$ from $\rho_{x=0.03}=44.8 \mu \Omega \cdot \mathrm{m}$ to $\rho_{x=0.10}=$ $1367.8 \mu \Omega \cdot \mathrm{m}$. For a $p$-type semiconductor, this is possible only provided that the concentration of the main current carriers, which are free holes, decreases when Sc atoms occupy vacancies in the crystallographic position $4 a$, and also the donors which compensate acceptor states are formed by vacancies in the crystallographic position $4 \mathrm{c}$ of $\mathrm{Ni}$ atoms. This conclusion is also confirmed by the behavior of the thermopower coefficient $\alpha(x, T)$ at concentrations $x \geq 0.03$.

Synthesis and study of electron transport characteristics of the $\mathrm{Er}_{1-x} \mathrm{Sc}_{x} \mathrm{NiSb}$ solid solution samples based on the $p$-ErNiSb half-Heusler phase indicate their prospects as a basis for the searching of the new thermoelectric materials. The investigation of the $\mathrm{Er}_{1-x} \mathrm{Sc}_{x} \mathrm{NiSb}$ solid solution alloys with higher concentrations of Sc atoms will allow us to clarify the mechanism of including impurity atoms into the matrix of the half-Heusler ErNiSb phase, which will be the subject of our further work.

\section{Conclusions}

Thus, the introduction into the $p$-ErNiSb semiconductor impurity Sc atoms by substitution of $\mathrm{Er}$ atoms in position $4 a$ is accompanied by the occupation of Sc atoms of available in the compound vacancies in the crystallographic position $4 a$, which results in the reduction and elimination of structural defects of acceptor nature and corresponding acceptor band $\varepsilon_{\mathrm{A}}^{E r}$. At the same time, the structural defects of donor nature are generated in the $4 a$ position, and an impurity donor band $\varepsilon_{D}^{S c}$ appears. The concentration ratio of ionized acceptors and donors generated in the $\mathrm{Er}_{1-x} \mathrm{Sc}_{x} \mathrm{NiSb}$ solid solution will determine the position of the Fermi level $\varepsilon_{F}$ and the mechanisms of electrical conductivity.

A detailed study of the semiconductive solid solution $\mathrm{Er}_{1-x} \mathrm{Sc}_{x} \mathrm{NiSb}$ at higher concentrations of impurity $\mathrm{Sc}$ atoms until the complete replacement of $\mathrm{Er}$ atoms $(x=1)$, as well as modeling of the electronic structure will allow more clearly formulate the conditions for obtaining thermoelectric material with high values of the figure of merit.

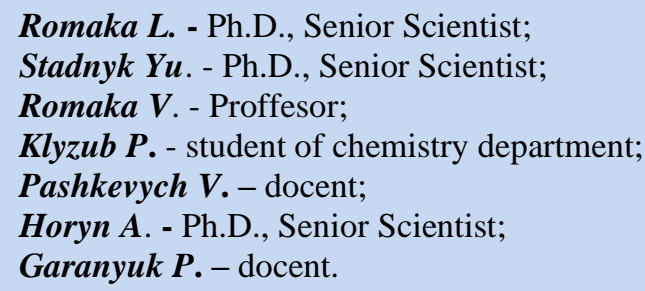

[1] R.V. Skolozdra, A. Guzik, A.M. Goryn, J. Pierre, Acta Phys. Polonica A 92, 343 (1997).

[2] V.A. Romaka, Yu.V. Stadnyk, V.Ya. Krajovskyj, L.P. Romaka, O.P. Guk, V.V. Romaka, M.M. Mykyychuk, A.M. Horyn, New thermosensitive materials and temperature converters (Lviv Polytech. Univ., 2020).

[3] L.I. Anatychuk, Thermoelements and thermoelectric devices (Naukova dumka, Kyiv, 1979).

[4] Karla, J. Pierre, R.V. Skolozdra, J. Alloys Compd. 265, 42 (1998) (https://doi.org/10.1016/S09258388(97)00419-2).

[5] O.A. Geraschenko, A.N. Gordov, A.K. Eremina, V.I. Lach, Ya.T. Lutsyk, V.I. Putsylo, B.I. Stadnyk, N.A. Yaryshev, Temperature measurements (Naukova dumka, Kyiv, 1989).

[6] L.P. Romaka, D. Kacharovski, A.M. Horyn, Yu.V. Stadnyk, V.Ya. Krayovskyy, V.V. Romaka, Phys. Chem. Sol. St. 17(1), 37 (2016) (https://doi.org/10.15330/pcss.17.1.37-42).

[7] V.V. Romaka, L. Romaka, A. Horyn, Yu. Stadnyk, J. Alloys Compd. 855, 157334 (2021) (https://doi.org/10.1016/j.jallcom.2020.157334).

[8] [V.A. Romaka, Yu. Stadnyk, L. Romaka, V. Krayovskyy, A. Horyn, P. Klyzub, V. Pashkevych, Phys. Chem. Sol. St. 21(4), 689 (2020) (https://10.15330/pcss.21.4.689-694).

[9] Wolanska, K. Synoradzki, K. Ciesielski, K. Zaleski, P. Skokowski, D. Kaczorowski, Mater. Chem. Phys. 227, 29 (2019) ( https://doi.org/10.1016/j.matchemphys.2019.01.056).

[10] K. Synoradzki, K. Ciesielski, I. Veremchuk, H. Borrmann, P. Skokowski, D. Szymanski, Y. Grin, D. Kaczorowski, Materials 12, 1723 (2019) (https://doi:10.3390/ma12101723).

[11] T. Roisnel, J. Rodriguez-Carvajal, Mater. Sci. Forum, Proc. EPDIC7 378-381, 118 (2001) (https://doi.org/10.4028/www.scientific.net/MSF.378-381.118).

[12] S. Babak, V. Babak, A. Zaporozhets, A. Sverdlova, Proceeds. Second Intern. Workshop on Computer Modeling and Intelligent Systems (CMIS-2019), Zaporizhzhia, Ukraine, April 15-19, 2019. 810 (2019). (CEUR Workshop Proceedings, Vol. 2353) (http://ceur-ws.org/Vol-2353/paper64.pdf).

[13] B.I. Shklovskii, A.L. Efros, Electronic Properties of Doped Semiconductors (Springer-Verlag, NY, 1984) (http://doi10.1007/978-3-662-02403-4).

[14] N.F. Mott, E.A. Davis, Electronic Processes In Non-crystalline Materials (Clarendon Press, Oxford, 1979). 
L. Romaka, Yu. Stadnyk, V.A. Romaka, P. Klyzub, V. Pashkevych, A. Horyn, P. Garanyuk

Л. Ромака ${ }^{1}$, Ю. Стадник ${ }^{1}$, В.А. Ромака ${ }^{2}$, П. Клизуб ${ }^{1}$, В. Пашкевич ${ }^{2}$, А. Горинь ${ }^{1}$, П. Гаранюк ${ }^{2}$

\section{Синтез і електротранспортні властивості напівпровідникового твердого розчину $\mathrm{Er}_{1-x} \mathrm{Sc}_{x} \mathrm{NiSb}$}

\footnotetext{
${ }^{1}$ Львівський наиіональний університет ім. І.Франка, Львів, Україна, lyubov.romaka@gmail.com ${ }^{2}$ Національний університет “Львівська політехніка”, Львів, Україна, volodymyr.romaka@gmail.com

Методом електродугового плавлення синтезовано зразки твердого розчину $\mathrm{Er}_{1-x} \mathrm{Sc}_{x} \mathrm{NiSb}(x=0-0.10)$ та досліджено вплив легування атомами Sc на електрокінетичні та енергетичні характеристики фази півГейслера ErNiSb за температур 80 - 400 К. Встановлено, що за досліджених концентрацій $\mathrm{Er}_{1-x} \mathrm{Sc} \mathrm{c}_{x} \mathrm{NiSb}$ основними носіями електрики в напівпровіднику є дірки. Показано, що легування $p$-ErNiSb атомами Sc шляхом заміщення у позиції $4 a$ атомів Er супроводжується зайняттям ними наявних вакансій у позиції $4 a$, що веде до зменшення та ліквідації структурних дефектів акцепторної природи та відповідної акцепторної зони. При цьому у позиції $4 a$ генеруються структурні дефекти донорної природи та 3'являється домішкова донорна зона. Співвідношення генерованих іонізованих акцепторів і донорів визначає положення рівня Фермі та механізми електропровідності $\mathrm{Er}_{1-x} \mathrm{Sc}_{x} \mathrm{NiSb}$. Досліджений твердий розчин $\mathrm{Er}_{1-x} \mathrm{Sc}_{x} \mathrm{NiSb} €$ перспективним термоелектричним матеріалом.
}

Ключові слова: напівпровідник, електропровідність, коефіцієнт термо-ерс, рівень Фермі. 